\title{
Análise morfossedimentar da praia, antepraia e plataforma continental interna da linha de costa do Parque Nacional de Jurubatiba - Rio de Janeiro
}

\author{
The morpho-sedimentary analysis of the beach shoreface inner \\ continental shelf system in front of the National Park of the Restinga \\ de Jurubatiba - Rio de Janeiro
}

Giseli Modolo Vieira Machado*

*Doutoranda em Oceanografia Ambiental/UFES; giselimodolo@gmail.com

\section{RESUMO}

A análise morfossedimentar do sistema praia-antepraia-plataforma continental interna objetiva caracterizar e identificar os processos hidrodinâmicos e morfossedimentares atuantes no referido sistema e analisar mais detalhadamente a aplicação do conceito de perfil de equilíbrio (Dean 1977). É avaliada a hipótese de que o recobrimento sedimentar na antepraia não controla a forma do perfil de equilíbrio, sendo o substrato reliquiar da antepraia o dominador de tal formato. Análises histórico-geomorfológicas, oceanográficas e sedimentológicas da área e observações de campo permitiram avaliar a estabilidade da linha de costa na faixa costeira do Parque Nacional da Restinga de Jurubatiba - Rio de Janeiro. A forte erosão observada na praia manifestou-se de maneira pontual, consequência de variações de: altura das ondas, principalmente de sul, sudoeste e sul-sudoeste; sedimentos finos e lamosos na antepraia e na plataforma continental interna e orientação da linha de costa. O estado morfodinâmico refletivo da praia e a presença de areia muito fina e lama na antepraia dificultam o deslocamento transversal dos sedimentos, incumbindo a deriva litorânea do papel principal de manutenção do material grosso neste sistema. O histórico geológico-geomorfológico transgressivo da área favorece também uma maior instabilidade deste litoral. Os desequilíbrios morfológicos observados na praia são compensados pelo grande volume de sedimentos mobilizados pela corrente longitudinal de sentido sudoeste-nordeste. A aparente estabilidade desta praia pode estar comprometida caso ocorram alterações do padrão de ondas, como, por exemplo, a intensificação das frentes frias, e/ou, cesse ou seja reduzido o trânsito longitudinal de sedimentos.

Palavras-chave: Antepraia; Plataforma continental interna; Perfil de equilíbrio

\begin{abstract}
The morpho-sedimentary analysis of the beach-shoreface-inner continental shelf system in front of the National Park of the Restinga de Jurubatiba - Rio de Janeiro was undertaken in order to characterize and to identify the hydrodynamic and morpho-sedimentary processes in the related system and to make a further analysis of the application of the concept of equilibrium profile (Dean 1977). It evaluated the hypothesis that the coating on shoreface sediment doesn't control the shape of the profile of equilibrium, being the substrate of relict shoreface the dominator in such a format. An analyzis of historical and geomorphological, sedimentological and oceanographic area and field observations allowed us to evaluate the stability of the shoreline. The strong erosion observed in different segments of the beach was clearly related to variations in South, Southwest and South-Southwets wave height, orientation of the shoreline as also to sediment characteristics of the shoreface and the inner continental shelf. The occurrence of patches of very fine sand and mud in the shoreface inhibited the onshore transport of medium to coarse sands to the beach leaving to the littoral drift the main function in providing the sediments for the equilibrium of the beach. The transgressive history of the geologic-geomorphologic evolution of the area also favors the instability of this coast. The observed morphologic disequilibrium in the beach is partially compensated by the volume of mobilized sediments through the northward directed longshore transport. Therefore modifications of the resulting direction or intensity of the longshore sediment transport due to modification of the wave climate will result in increased instability of a system already under stress.
\end{abstract}

Keywords: Shoreface; Inner continental shelf; Equilibrium profile 


\section{Introdução}

A zona costeira comporta-se como um sistema ambiental instável em função de uma série de processos geológicos continentais e marinhos que são determinantes na formação de distintos tipos de costa (Silva et al. 2004) - por exemplo, as praias arenosas, que refletem na sua mobilidade morfológica não só as condições distintas do clima de ondas, mas também o contexto evolutivo da planície (Bastos 1997), como observado pelo autor no litoral norte fluminense, ao sul do Cabo de São Tomé, onde os estreitos cordões arenosos transgressivos indicam uma linha de costa retrogradante.

Os diversos tipos de praias submetidos aos variados regimes de maré, de onda e de suprimento de sedimentos apresentam, segundo Jackson et al. (2005), estados morfodinâmicos substancialmente controlados pela geologia. Conforme os autores, na maioria das 25 praias estudadas na costa norte da Irlanda, o controle geológico aparece para limitar até mesmo a influência da dinâmica atual na morfologia praial.

Este artigo se propõe a estudar sistematicamente a praia e a zona submarina adjacente à orla do Parque Nacional de Jurubatiba, localizado no flanco sul da planície costeira deltiforme do rio Paraíba do Sul, situado no estado do Rio de Janeiro, Brasil.

Objetiva analisar a influência do substrato reliquiar da antepraia no controle da forma do perfil de equilíbrio, para compor, juntamente com as análises morfológicas, oceanográficas e sedimentológicas, uma avaliação dos processos erosivos envolvidos nesta linha de costa. Para isto, foi necessário analisar mais detalhadamente a aplicação do conceito de perfil de equilíbrio proposto por Dean (1977), bem como testar a escolha do local da coleta do sedimento para o referido perfil. Posteriormente, a estabilidade da linha de costa foi avaliada sob a inferência dos principais padrões de transporte sedimentar na plataforma continental interna e na antepraia, possivelmente envolvidos nas evidências erosivas encontradas em campo.

Enfim, este trabalho enfoca a distribuição e o transporte de sedimentos na praia, antepraia e plataforma continental interna; os aspectos morfodinâmicos do sistema praial; a identificação de tendências de vulnerabilidade; e, finalmente, a influência do substrato reliquiar na definição do perfil de equilíbrio.

\section{Caracterização da área}

A área de estudo se localiza no litoral norte fluminense, abrangendo as praias e a plataforma continental interna compreendidas entre os distritos de Cabiúnas (município de Macaé), ao sul, e proximidades da Barra do Furado (município de Quissamã), ao norte, defronte ao Parque Nacional de Jurubatiba, incluindo aproximadamente $44 \mathrm{~km}$ de costa inserida na planície arenosa costeira (figura 1).
O litoral é caracterizado por um terraço pleistocênico formado de cristas de praia e um estreito cordão litorâneo holocênico transgressivo (Dominguez et al. 1981, Muehe \& Valentini 1998, Martin et al. 1984), precedendo um conjunto de pequenas lagunas.

Estas feições geomorfológicas são denominadas por Dias \& Silva (1984) de restingas duplas, caracterizadas, pelo menos, por dois eventos transgressivos.

Segundo os autores, à retaguarda do cordão litorâneo existe um conjunto de pequenas lagunas, que se estreita em direção à planície pleistocênica, podendo ser caracterizada pelo aspecto truncado das margens lagunares, em contato como reverso do cordão litorâneo e pela presença de cúspides internas, sugerindo que estas lagunas eram mais largas do que a configuração atual (figura 2).

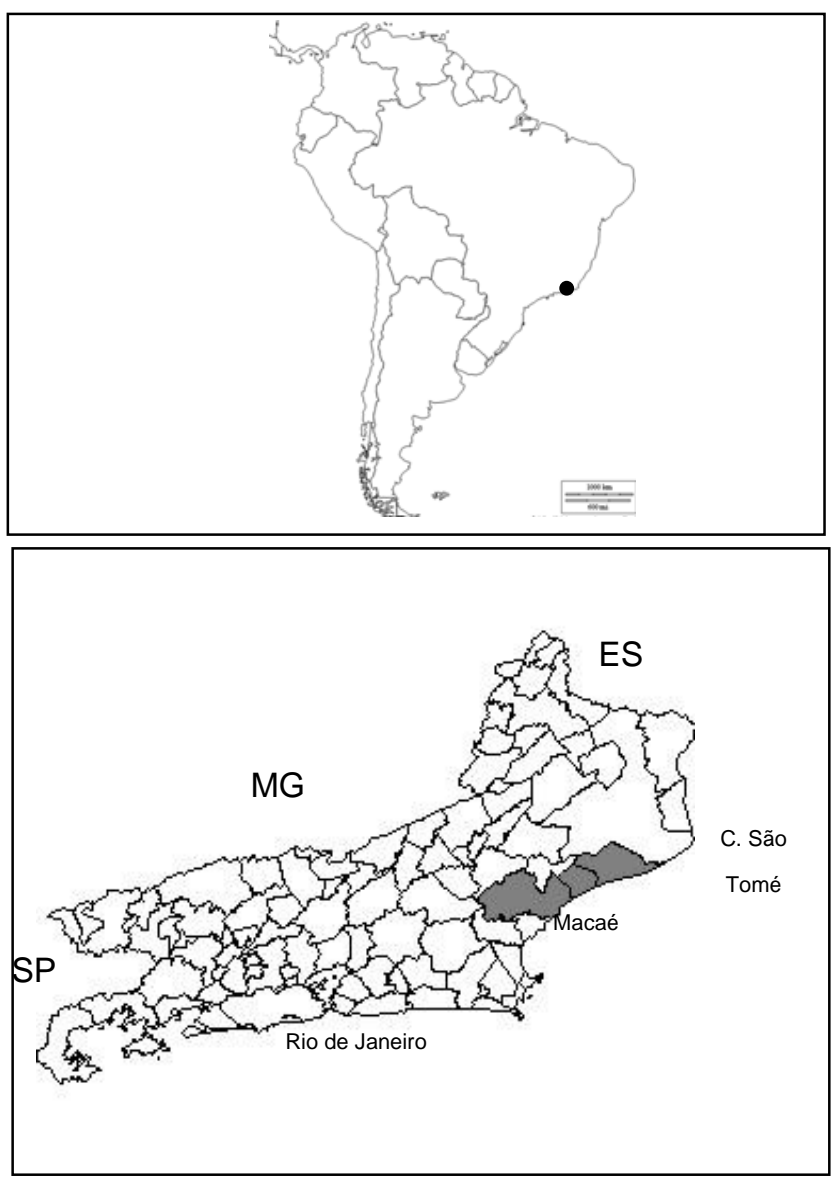

Figura 1: Localização da área de estudo

De acordo com Martin et al. (1984), no flanco sul da planície costeira do Paraíba do Sul os terraços pleistocênicos são particularmente bem desenvolvidos, sendo datados em 120.000 anos A.P. Já, o cordão litorâneo é mais recente que 5.100 anos A.P. Este aparece restrito a uma barreira arenosa única de algumas dezenas de metros de largura, e seus sedimentos são provenientes principalmente da plataforma continental interna (Martin et al. 1984, Muehe 2005). 
As flutuações do nível relativo do mar são, segundo Suguio et al. (1985) e Dominguez et al. (1981), um dos principais fatores responsáveis pela sedimentação costeira durante o Holoceno, consistindo consequentemente no fator decisivo para a configuração morfológica atual da linha de costa da planície ao sul do Cabo de São Tomé, caracterizado por dois episódios transgressivos Quaternários: Penúltima e Última Transgressão.

$\mathrm{Na}$ Penúltima Transgressão (Transgressão Cananéia), com máxima atingida a cerca de 120.000 anos A.P, o nível do mar erodiu total ou parcialmente os depósitos continentais, formando então, com o subsequente evento regressivo do mar, terraços arenosos pleistocênicos. Após este evento regressivo iniciou-se a Última Transgressão (Transgressão Santos) - holocência - na qual o mar atingiu cerca de $5 \mathrm{~m}$ acima do nível atual, por volta de 5.100 anos A.P., erodindo e afogando parcialmente as planícies costeiras e cursos fluviais, isolando o sistema lagunar. A subsequente descida do nível relativo do mar levou à construção de terraços marinhos a partir de ilhabarreira original, resultando na progradação da linha de costa com os denominados cordões arenosos holocênicos, causando também uma gradual

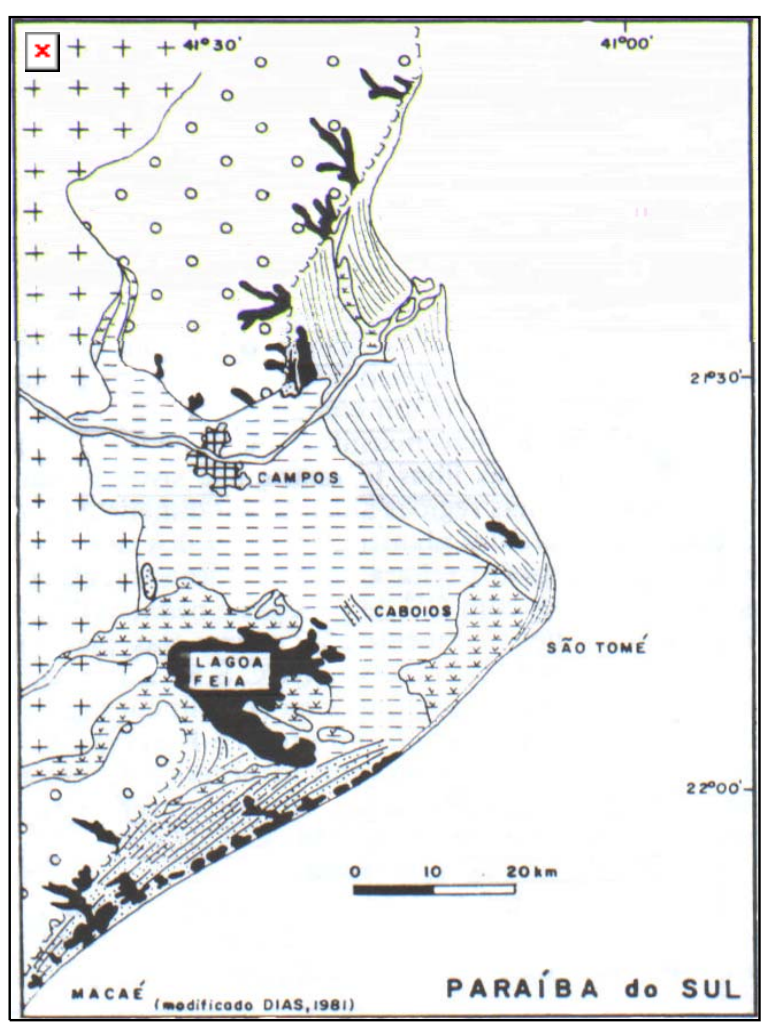

transformação das lagunas em lagoas, e estas em pântanos salobros e, finalmente, doces.

Para uma caracterização climática, a área de estudo está inserida na costa leste do Brasil, que vai de Cabo Frio (RJ) até o paralelo de $10^{\circ} \mathrm{S}$, e esta localização faz com que a região seja afetada por dois padrões de ondas, um de NE e outro de SE, associados aos ventos alísios originários do anticiclone do Atlântico Sul, este último reforçado pelo avanço da Frente Polar Atlântica (Dominguez \& Bittencourt 1994).

Com relação aos aspectos oceanográficos, a orla estudada recebe com maior frequência ondas fracas a moderadas, associadas aos ventos locais dos quadrantes NE e E, com períodos de pico máximo de 7 segundos e altura significativa média de $1,3 \mathrm{~m}$, não ultrapassando 1,8m (Souza 1988). E com maior intensidade, no entanto, menos frequentes, a região é influenciada por ondas provenientes dos quadrantes $\mathrm{SE}, \mathrm{S}$ e $\mathrm{SW}$, associadas às frentes frias durantes os meses de outono e inverno. Conforme a autora, o mar de SW, apesar de ocasional, proporciona a pior situação: ondas significativas máximas de aproximadamente $5 \mathrm{~m}$ de altura e período de pico de 12,6 segundos.

Figura 2: Mapa geológico da feição deltaica do Paraíba do Sul (Dominguez et al. 1981)

Conforme as observações de Souza (1988), a altura média (Ho) das ondas situa-se entre 1,6 e $2 \mathrm{~m}$. Alturas superiores a $3 \mathrm{~m}$ são mais frequentemente oriundas dos quadrantes S e SW.
Devido às condições oceanográficas, o transporte litorâneo residual é orientado para o norte (Gusmão 1990, Cassar \& Neves 1993 apud Muehe \& Valentini 1998, Bastos 1997), em adaptação às ondas de SE, geradas pelas 
frentes frias ou as que chegam na forma de marulho, oriundas das latitudes mais elevadas do Sul (Muehe \& Valetini 1998).

Segundo Muehe (2004), a praia em estudo é classificada quanto à hidrodinâmica como uma praia exposta e de alta energia, pois é desprotegida das ondas de tempestades; quanto à morfodinâmica, é classificada como refletiva, pois apresenta baixa variabilidade topográfica entre a praia e a antepraia, com ondas do tipo mergulhante e ascendente; e, quanto à morfologia, a praia é destacada do litoral, pois está separada da retroterra por corpos d'água.

Quanto à descrição das feições morfológicas do sistema praial, foram fixadas algumas terminologias em função da falta de consenso entre diversos autores na delimitação e caracterização das feições praiais. Neste trabalho, foram adotados limites e nomenclaturas propostos por Muehe (2001) (figura 3).

A praia, seja sua parte emersa ou submersa, é referida ao sistema praial. Tal sistema se divide em pós-praia e antepraia, sendo a primeira composta pela pós-praia (berma) e face praial, e a segunda composta pelas antepraias superior, média e inferior.

Segundo Muehe (2001), as praias são depósitos de sedimentos acumulados por ação das ondas que, por apresentar mobilidade, se ajustam às condições de ondas e maré. A pós-praia é a porção sub-horizontal (terraço), formada por sedimentação de areia por ação das ondas (Suguio 1992) em ocasiões de tempestade ou marés excepcionais (Mendes 1984).

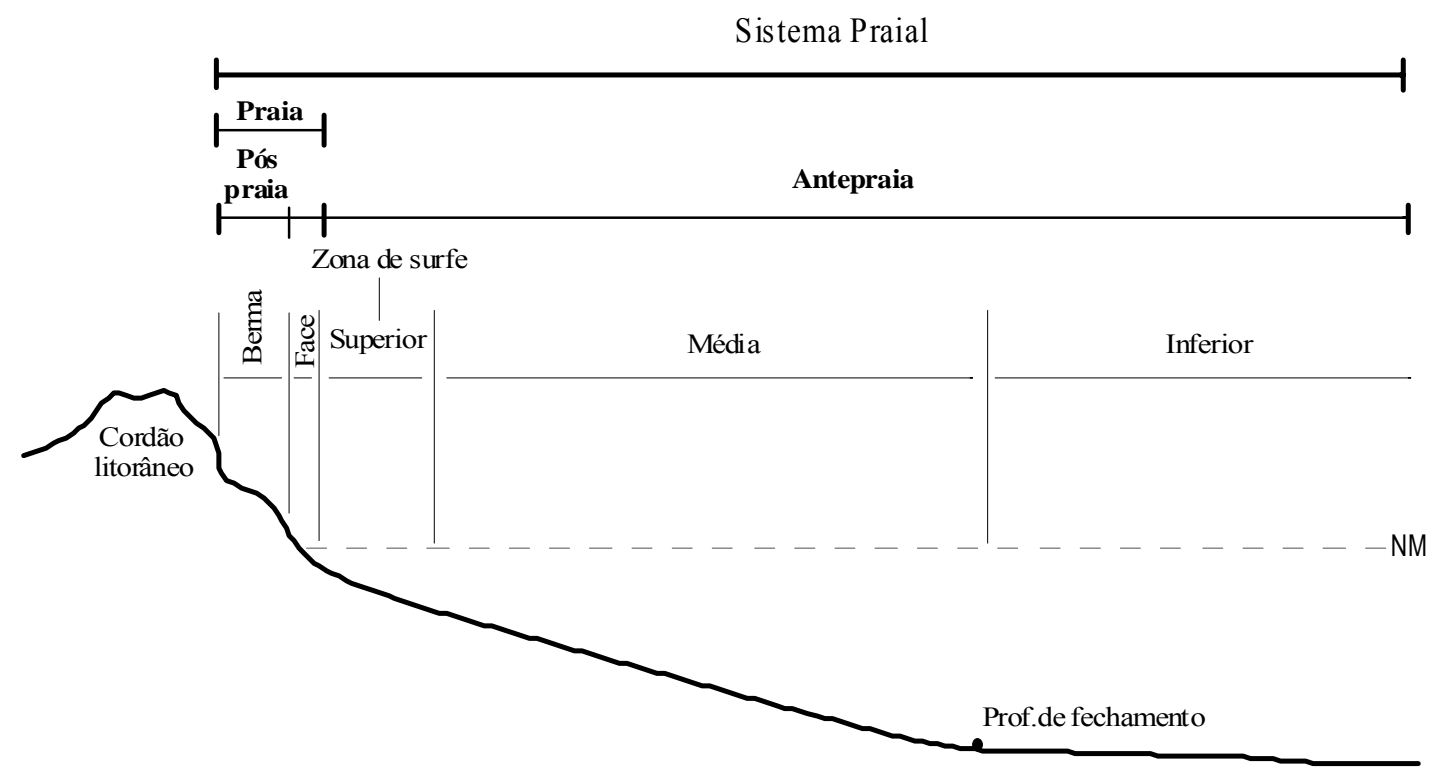

Plat. Cont. Interna

Figura 3: Terminologias e limites adotados nas feições do sistema praial para praias tipicamente refletivas

Da pós-praia rumo ao continente, é comum a presença de dunas, cordões e falésias, mas elas não fazem parte da praia propriamente dita, apesar de estas feições sofrerem esporadicamente as influências da ação das ondas e constituírem armadilhas ou retentores de sedimentos do sistema praial.

A face da praia é uma feição pertencente à praia, situada numa faixa de transição entre a pós-praia e a antepraia.

A antepraia compreende o prisma sedimentar submarino de transição entre a plataforma continental interna e a praia, e é caracterizada por um contínuo incremento do gradiente topográfico em direção ao litoral (Muehe 2006)

Segundo Muehe et al. (2001), a antepraia pode ser dividida em três partes (no sentido terra-mar): a superior, que compreende a zona de surfe, limitada externamente no ponto de arrebentação da onda; a média, que envolve o trecho até a profundidade de fechamento; e a inferior, que compreende, em média, o dobro do comprimento da antepraia média (figura 3 ).
Os sedimentos da face da praia da orla do Parque de Jurubatiba são de areia grossa a muito grossa, ao contrário da antepraia, que é recoberta por sedimentos arenosos muito finos e lamosos, resultando em um gradiente topográfico suave, que contrasta com a face da praia muito íngreme, onde essa transição se faz de modo abrupto (Muehe 1998b).

A plataforma continental interna apresenta largura em torno de $35 \mathrm{~km}$ (Muehe 1998a) e é caracterizada por baixo gradiente topográfico (Carvalho \& Rizzo 1994). A declividade da face da praia atual e da plataforma entre Barra do Furado e Macaé apresenta um gradiente em torno de 1:560 $\left(0,1^{\circ}\right)$, e nas proximidades de Macaé esta fica próxima de 1: $2.900\left(0,01^{\circ}\right)$ (Silva 1987, Kowsmann et al. 1979).

Os sedimentos superficiais da plataforma continental interna são predominantemente terrígenos, ou seja, de origem fluvial, provavelmente da paleodesembocadura do rio Paraíba do Sul, representados por areias quartzosas com baixo teor de carbonatos (Alves \& Ponzi 1984).

Ocorre também a presença de lama disposta paralelamente à linha de costa nas proximidades da isóbata 
de 20 metros na plataforma continental interna entre o Cabo Búzios e Macaé (Fernandez 1995, Muehe 1998a), evidenciando uma provável faixa de lama que se estende para norte de Macaé, devido ao transporte litorâneo dado preferencialmente de sul para norte (Gusmão 1990, Cassar \& Neves 1993 apud Muehe \& Valentini 1998, Bastos 1997, Dominguez et al. 1983, Dominguez 1987 apud Dominguez \& Bittencourt 1994).

A distribuição sedimentológica da plataforma continental externa é caracterizada pela presença de sedimentos tipicamente carbonáticos, representados principalmente por algas calcáreas nodulares ramificadas (Alves \& Ponzi 1984) e atinge quase $150 \mathrm{~km}$ nas proximidades de Macaé (Carvalho \& Rizzo 1994). Estes sedimentos afetam apenas marginalmente a área de estudo, indicando que não contribuem para o balanço sedimentar da antepraia, pois esta é constituída por material siliciclástico; ou seja, a plataforma continental externa não disponibiliza atualmente sedimento para o sistema praia-antepraia-plataforma continental interna.

Quanto à batimetria da plataforma continental interna, as costas próximas à linha de costa apresentam, até os $10 \mathrm{~m}$, isolinhas paralelas a esta. A partir da profundidade de $15 \mathrm{~m}$, na parte nordeste do mapa, as isolinhas apresentam-se mais afastadas, direcionadas para sudoeste até aproximadamente $65 \mathrm{~m}$ de profundidade, evidenciando uma topografia mais suavizada da plataforma continental (figura 4). Este banco submarino de orientação NE-SW indica, provavelmente, um antigo delta (Kowsmann et al. 1979), correspondendo à paleodesembocadura do rio Paraíba do Sul.

Abaixo de $50 \mathrm{~m}$, na porção leste do mapa batimétrico (figura 4), ocorre uma mudança fisiográfica importante com direção sul-norte, onde as linhas batimétricas se distribuem de forma mais irregular e às vezes muito próximas umas das outras, representando um canal submarino de gradiente topográfico mais acentuado, indicando ser um paleocanal fluvial (Kowsmann et al. 1979) que se estende da isóbata de 56 até a de $74 \mathrm{~m}$ (Silva 1987).

Nas isóbatas próximas à linha de costa, onde se situa a antepraia, até aproximadamente a isolinha de $10 \mathrm{~m}$, não se verifica significativa diferença na declividade do fundo, devido provavelmente à escala do mapa. No entanto, trabalhos já realizados (Silva 1987, Kowsmann et al. 1979) apontam um gradual aumento do gradiente topográfico em direção a nordeste. Assim, a declividade da antepraia e da plataforma continental interna torna-se mais acentuada no sentido nordeste, mantendo-se ainda com um gradiente de baixa declividade.

\subsection{Estabilidade da linha de costa}

O desequilíbrio no balanço sedimentar pode provocar graves alterações na linha de costa, muitas vezes induzidas por retenção de sedimentos por obras de engenharia, exaustão das fontes supridoras, readaptação do perfil de equilíbrio a uma elevação do nível do mar e modificação do clima de ondas, que juntos ou isoladamente causam a redução no aporte sedimentar, sendo responsáveis pelos processos erosivos e consequentes alterações na linha de costa (Muehe 2004).

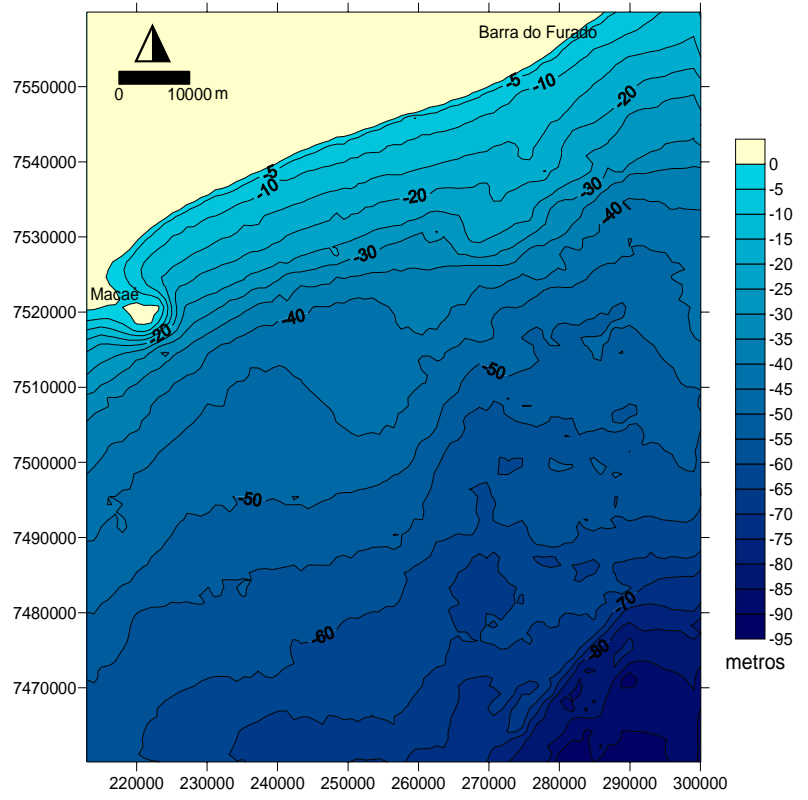

Figura 4: Mapa batimétrico gerado a partir da Folha de Bordo (FB-1500 001/80)

Segundo Muehe (2004), os efeitos de uma elevação do nível do mar em costas caracterizadas por cordão litorâneo estreito, com existência de lagunas à retaguarda, é o alagamento e aumento da profundidade das lagunas. Onde os cordões são largos, ocorre erosão na borda oceânica, instalando-se o processo de migração apenas quando a largura e altura permitirem a ultrapassagem das ondas.

Em consequência da baixa declividade da plataforma continental interna, a retrogradação da linha da costa pode atingir dezenas de metros e, em alguns casos, até mesmo quilômetros (Muehe 2004).

\subsection{Perfil de equilíbrio}

O conceito de perfil de equilíbrio evidenciado a partir da Regra de Bruun (1954) é inicialmente aplicado a processos de escala geológica para ajuste gradual do perfil transversal às diferentes situações do nível do mar. Atualmente, esse conceito é aplicado nos processos de menor escala, e sua utilização é uma maneira fácil de fazer a estimativa do valor do recuo da linha de costa por ação de ataque frontal das ondas, sendo, portanto, considerado um conceito altamente dinâmico (Dean 1977).

Para Dean (1977, 1991), o conceito de perfil de equilíbrio considera algumas hipóteses, entre elas: que o movimento de sedimentos é dado somente por transporte transversal; que a antepraia é rica em areia, e a estrutura geológica subjacente não influencia na forma do perfil, pois a abundância de sedimentos é capaz de modelá-lo; que a profundidade de fechamento existe e pode ser quantificada; e que o perfil de equilíbrio representa uma aproximação da forma real da antepraia, podendo ser usado para fins 
práticos, como, por exemplo, para um projeto de recuperação de praia.

O modelo teórico de cálculo de perfil de equilíbrio de Dean (1977) é expresso pela equação (1),

$$
h(x)=A x^{m=0,67}
$$

onde $h(x)$ é a profundidade da água a uma distância $x$ da linha de praia; $A$ é o parâmetro escalar empírico relacionado ao diâmetro mediano ou à velocidade mediana de decantação do sedimento; e $m$ é o coeficiente empírico, com valor de 0,67 ou $2 / 3$.

\subsection{Deslocamento de sedimento}

As fontes mais prováveis dos sedimentos arenosos com destino às regiões litorâneas são os cursos fluviais adjacentes e, principalmente, da plataforma continental interna (Muehe 2005). Para tal destino, são necessários mecanismos de transporte sólido na água, capazes de deslocar esse material até a praia, ou quem sabe, relocálo na plataforma.

Mudanças ocorridas nos perfis transversais de praia envolvem, principalmente, um intercâmbio de sedimentos em direção ao continente e em direção ao mar. Este trajeto depende das correntes litorâneas e do padrão de movimentos orbitais assimétricos de ondas em águas rasas, incluindo a arrebentação e a zona de surfe. $\mathrm{O}$ transporte de sedimentos em direção ao continente é mais efetivo com os sedimentos mais grossos, pois as maiores partículas são movidas somente durante a velocidade mais rápida do movimento orbital (Bagnold 1940 apud Komar 1976); e as areias mais finas e o silte tendem a se mover numa distância quase igual em ambas as direções (onshore-offshore), com resultante do transporte em direção ao mar (Cornish 1898 apud Komar 1976).

$\mathrm{Na}$ região onde as ondas alcançam o fundo, as partículas são transportadas por arrasto. $\mathrm{Na}$ região da zona de surfe, devido à turbulência, o transporte se dá por suspensão, sendo facilmente transportado paralelamente à linha de costa pelas correstes longitudinais, ou em direção ao mar pelas correntes de retorno (Horikawa 1972).

\section{Metodologia}

Foram realizadas duas campanhas: janeiro de 2005 e fevereiro de 2006. Nesta pesquisa foram desempenhadas as seguintes tarefas: definição dos pontos de amostragem para os perfis transversais e para a coleta de sedimentos na praia, na antepraia e na plataforma continental interna; confecção de mapa batimétrico para possibilitar a modelagem de refração de ondas; confecção de perfis topo-batimétricos e de perfis de equilíbrio; cálculo da energia da onda, da velocidade e do volume estimado do transporte longitudinal; análise granulométrica dos sedimentos coletados; identificação e caracterização da direção do transporte e dos ambientes deposicionais na plataforma continental interna.

Foram definidos seis perfis topográficos $(\mathrm{P} 1, \mathrm{P} 2, \mathrm{P} 3, \mathrm{P} 4$, P5 e P6), separados aproximadamente $11 \mathrm{~km}$ uns dos outros, e 10 perfis transversais submersos na plataforma continental interna (A, B, C, D, E, F, G, H, I e J, equidistantes cerca de 3 milhas náuticas) para a coleta de sedimentos. Cada perfil submerso apresentou 10 pontos de coleta (separados com cerca de 0,75 milha náutica, figura 5).

Os sedimentos foram coletados no reverso e no topo do cordão litorâneo, na berma, na face, na zona de surfe e antepraia média (profundidade em torno de 5,5m) e na plataforma continental interna.

As cotas batimétricas foram extraídas da Folha de Bordo do Cabo de São Tomé-RJ e georreferenciadas e digitalizadas no Software Didger 3.0 (Golden Software Inc). Posteriormente, o mapa batimétrico foi confeccionado no Software Surfer 8.0 (Golden Software Inc).

Para o levantamento dos perfis topo-batimétricos, foi utilizada a técnica sugerida por Muehe (2006). Esta visa ao acoplamento do perfil topográfico da praia ao perfil batimétrico da antepraia, amarrado a um mesmo datum vertical através das coordenadas transferidas para um programa de navegação, acoplado a um sistema de posicionamento por satélite GPS (GPS TrackMaker), posicionado na embarcação e direcionado rumo à costa no sentido das coordenadas do perfil topográfico também inseridas no GPS.

As simulações de refração de ondas foram feitas por meio do programa MIKE 21NSW, considerando ondas de direções, períodos e alturas representativas do clima de ondas local. Foram simuladas ondas provenientes de NE com período de $7 \mathrm{~s}$, altura significativa média de $1,5 \mathrm{~m}$ e velocidade do vento de $5 \mathrm{~m} / \mathrm{s}$, representando as condições mais frequentes do mar, e ondas de Sul (S), Sudeste (SE), Sul-Sudeste (SSE), Sudoeste (SW) e Sul-Sudoeste (SSW), com período de $12 \mathrm{~s}$, altura significativa média de $3 \mathrm{~m}$ e vento de $10 \mathrm{~m} / \mathrm{s}$ de velocidade, associadas às frentes frias.

Após a confecção dos perfis topo-batimétricos, foram elaborados os perfis de equilíbrio da praia utilizando a equação de Dean (1977).

Para a averiguação desta equação, foram testados os valores do sedimento mediano $(M d)$, coletado na face da praia e na antepraia, visto que o sistema praia-antepraia analisado apresenta características granulométricas bastante distintas; e foi testado também o coeficiente empírico $m$ com valor de 0,4 referente ao estado morfodinâmico refletivo, como sugerido por Bowen (1980), Inman et al. (1993), Kotvojs \& Cowell (1991 apud Cowell et al. 1999). 


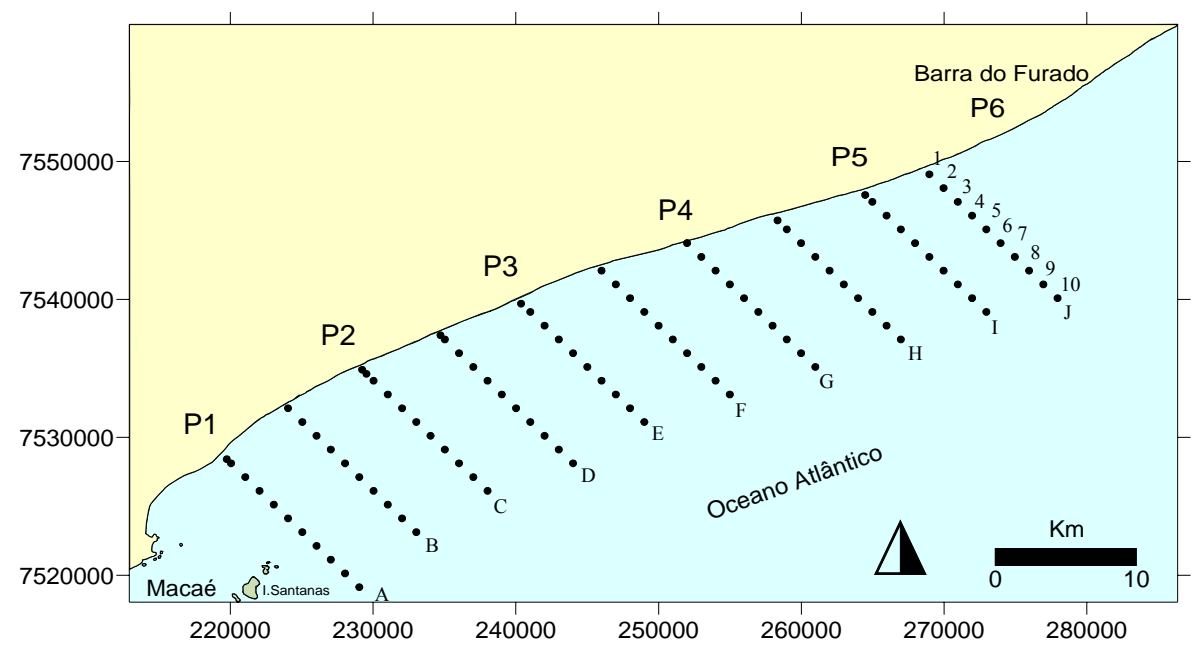

Figura 5: Localização dos pontos de amostragem dos perfis e da coleta de sedimentos na plataforma continental interna

Para a determinação do tamanho dos sedimentos, foi empregada a técnica de análise granulométrica por peneiramento a seco. As amostras com alto percentual de lama (acima de 5\%) foram submetidas também a pipetagem. No total, foram 126 amostras (23 da praia e 103 da plataforma) trabalhadas e interpretadas através dos parâmetros estatísticos (Folk \& Ward 1957) seguindo a escala de tamanho de classificação granulométrica adotada por Wentworth (1922). Os parâmetros foram trabalhados em fi $(\phi)$ para se alcançaros valores da mediana $(M d)$, da média $(M z)$, do desvio-padrão $\left(\sigma_{I}\right)$, da assimetria $\left(S k_{I}\right)$ e da curtose normalizada $\left(K_{G}^{\prime}\right)$.

A identificação da direção de transporte sedimentar foi testada através das técnicas de McLaren (1981) e McLaren \& Bowles (1985).

McLaren (1981) sugere que a média, o desvio-padrão e a assimetria da distribuição da frequência granulométrica permitam, durante o transporte, identificar: a direção do transporte, os processos sedimentares de selecionamento, a deposição seletiva e a deposição total. Uma vez estabelecidas essas tendências, pode-se indicar a trajetória do transporte dos sedimentos e o sentido da deriva litorânea (Bitencourt et al. 1992)

O modelo proposto por McLaren (1981) demonstra as mudanças relativas que ocorrem na seleção das estatísticas granulométricas entre o depósito e uma fonte hipotética. Essas mudanças requerem, segundo o autor, algumas suposições: 1) o depósito é o produto de uma única área fonte de sedimentos; 2) há uma maior probabilidade de os grãos finos (leves) se movimentarem do que os grãos mais grossos (pesados); 3) há uma maior probabilidade de grãos maiores serem depositados numa situação de transporte, do que os grãos finos.

McLaren \& Bowles (1985) apresentam um modelo mais refinado, que demonstra como a distribuição granulométrica dos depósitos sedimentares muda na direção do transporte: 1) os sedimentos em transporte devem ser mais finos, melhor selecionados e com assimetria mais negativa do que o sedimento de origem; 2) os sedimentos tardios devem se tornar mais grossos, melhor selecionados e com assimetria mais positiva; 3) os depósitos sucessivos podem se tornar mais finos, iguais ou mais grossos, mas a seleção deve ficar melhor e a assimetria mais positiva em relação às consideradas como fonte.

A caracterização dos ambientes deposicionais foi feita a partir da análise das distribuições granulométricas, empregando a classificação de Sahu (1964) e Passega (1964).

Sahu (1964) utilizou um método quantitativo de discriminação entre os diferentes mecanismos ou processos e os diferentes ambientes de deposição, a partir da distribuição granulométrica dos sedimentos clásticos mais grossos (cascalho, areia, silte e outros), com a fórmula empírica (2) capaz de distinguir mecanismos de ambientes marinhos de águas rasas agitadas (abaixo de 100m) e de praia.
Y praia: mar raso $=15,6534 \mathrm{Mz}+65,7091 \sigma_{l}^{2}+18,1071 S k_{l}+$ $18,5043 K_{G}$

$\mathrm{O}$ valor de $\mathrm{Y}_{\mathrm{u}}$ menor que 65,3650 indica ambiente deposicional de praia, e o maior indica ambiente deposicional marinho de águas rasas agitadas.

Para caracterizar os agentes deposicionais a partir da textura dos sedimentos, foi empregada a técnica de Passega (1964). Nesta, utilizam-se dois parâmetros de distribuição granulométrica: o primeiro percentil (C), ou seja, o diâmetro (fi) da fração mais grossa da amostra e o valor do diâmetro mediano $(\mathrm{M})$ da distribuição granulométrica, denominado de diagrama CM.

O diagrama CM revela diferentes processos de transporte e de sedimentação (Selley 1982), bem como as condições hidráulicas (Muehe 1989) sob as quais o sedimento foi depositado (figura 6).

Segundo verificado por Muehe (1989), quando os valores de C são menores que zero fi $(\Phi)$, ou seja, mais grossos, indicam que os grãos depositados estão próximos à área fonte. 
Log - Diâmetro mediano (fi)

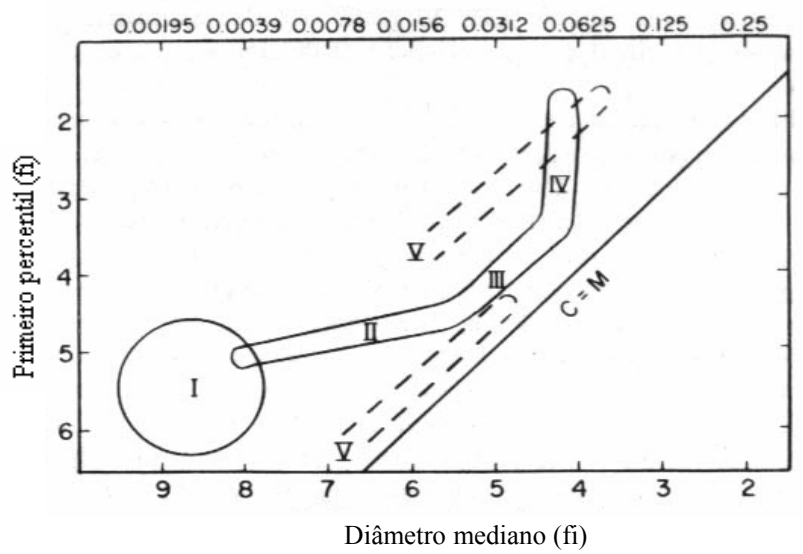

Figura 6: Diagrama CM de Passega (1964) (figura de Selley 1982)

Cada um desses segmentos mostrados na figura 6 representa um processo de sedimentação diferente: 1) transporte por suspensão pelágica; 2) suspensão uniforme; 3) suspensão graduada; 4) transporte em suspensão no fundo, sob condições de baixa turbulência; e 5) transporte através das correntes de turbidez, sob condições de alta turbulência.

\section{Resultados e discussão}

Caracterização morfossedimentar do sistema praiaantepraia-plataforma continental interna

A praia apresentou características refletivas: elevada declividade da face $\left(\sim 9^{\circ}\right)$ e reduzida largura da zona de surfe, às vezes inexistente. A transição entre a antepraia e a praia acontece de modo abrupto, devido ao elevado gradiente topográfico da face praial e da antepraia superior (zona de arrebentação e surfe).

A configuração dos seis perfis topográficos apresentou cordão litorâneo com cota máxima aproximada de $6 \mathrm{~m}$ de altitude e declividade bastante acentuada da face da praia. Verificou-se que a largura do cordão e a presença de vegetação sobre o mesmo não apareceram com a mesma intensidade ao longo de toda a orla do Parque, ocorrendo grandes trechos com ausência de vegetação e reduzida largura do cordão litorâneo, como, por exemplo, o trecho situado entre os Perfis 4 e 5.

De modo geral, as areias da praia apresentam granulometria grossa, moderado grau de seleção, pouca assimetria e curtose mesocúrtica a leptocúrtica. Já, as areias da zona da antepraia superior (zona de arrebentação e surfe) apresentam areias fina e muito fina e silte, com assimetria negativa, moderado grau de seleção e curtose na maior parte leptocúrtica. As areias da antepraia média (entre a zona de arrebentação e a profundidade de fechamento) apresentam diâmetro granulométrico mediano fino e muito fino, assimetria negativa, seleção de moderada a boa e curtose leptocúrtica. Os sedimentos da antepraia inferior (entre a profundidade de fechamento e a plataforma continental interna) apresentam-se bem mais finos, com presença significativa de lama, podendo ser classificados como lama siltosa. Enfim, as areias ao longo da praia contrastam com as areias da antepraia.

A distribuição granulométrica das amostras da plataforma continental interna está ilustrada na figura 7.

Manchas de lama (constituída em sua maioria por silte) situam-se paralelamente à linha de costa, principalmente do Perfil 3 até após o Perfil 4. É bastante significativa também a concentração de areia muito fina defronte aos Perfis 3, 4 e 5, margeando toda a mancha de lama (figura 7A).

Apesar da ocorrência de manchas de lama e de areia muito fina, boa parte dos sedimentos que recobrem a plataforma continental interna é composta de areia grossa e média. Estas frações se concentram de maneira bastante homogênea e apresentam-se com granulometria mais grossa à medida que se distanciam da linha de costa (figura 7A).

$\mathrm{Na}$ figura 7B nota-se que o pobre grau de seleção predominou nas áreas onde estão as areias fina e muito fina e lama. Nota-se também que o grau de seleção melhora em direção ao mar aberto, e piora à medida que se aproxima da costa.

A distribuição da assimetria (figura 7C) apresentou-se de forma bastante clara: manchas isoladas de assimetria positiva no trecho onde se localizam as lamas e as areias muito finas; simetria num extenso trecho paralelo à linha de costa; e assimetria negativa e muito negativa localizada à medida que se avança para o mar, e, também, próximas às adjacências dos Perfis 1 e 2, onde se encontram trechos com areia média e grossa.

A distribuição da curtose (figura 7D) mostrou predominância de amostras platicúrticas, o que indica ambientes deposicionais, localizados com mais expressividade próximo aos Perfis 4 e 5; as amostras leptocúrticas, indicando ambientes com predomínio de transporte, estão localizadas entre os Perfis 5 e 6 e num curto trecho entre os Perfis 2 e 3. Nota-se que entre as áreas de curtose platicúrtica e leptocúrtica estão as mesocúrticas, que indicam ambientes de transição. 
Quaternary and Environmental Geosciences (2010) 02(1):01-17

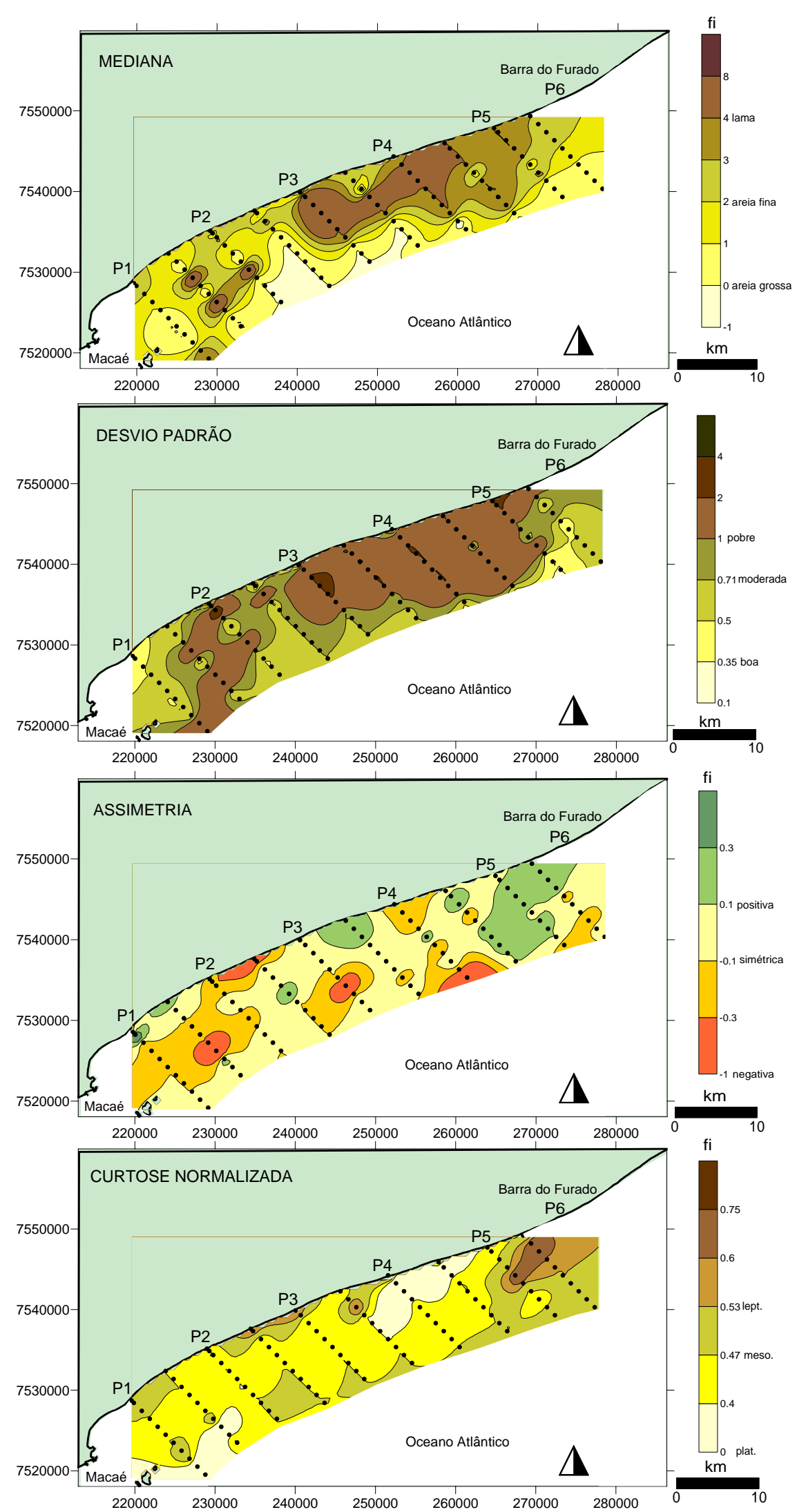

Figura 7: Mapas texturais e granulométricos da plataforma continental interna. (A) diâmetro mediano, (B) grau de seleção, (C) assimetria e (D) curtose normalizada 


\subsection{Refração de ondas}

A modelagem de refração de ondas simulou as seguintes situações: mar mais frequente, com ondas de $\mathrm{NE}$, associadas às condições de tempo bom; e ondas mais intensas provenientes do quadrante Sul (S, SE, SSE, SW e SSW), representando as condições de tempestades.

Embora praticamente todo o litoral analisado, exceto no Perfil 1, apresente forte exposição às condições mais energéticas de mar, trechos mais vulneráveis à erosão foram reconhecidos através da convergência da energia das ondas.

Nas ondulações de NE houve pouca variação de altura de onda, não ultrapassando $0,5 \mathrm{~m}$ de altura na linha de costa. Isto em função da própria incidência das ondas e da proteção do Cabo de São Tomé, permitindo uma região de sombra para a área.

As ondulações de S, SE, SSE, SW e SSW apresentaram variações na altura das ondas ao atingirem a praia, porém nunca inferior a $1,2 \mathrm{~m}$ podendo alcançar alturas superiores a $3 \mathrm{~m}$.
É válido ressaltar que a difração sofrida pelas ondas ao redor do arquipélago de Santana é responsável pelo processo de formação do tômbolo submarino, fazendo com que as ondas divirjam sua energia no reverso das Ilhas, provocando a convergência das ortogonais nas laterais (figura 8).

Foi observada concentração de energia ao largo do Perfil 5 para todas as situações de tempestades simuladas, as quais mantiveram uma constância de ondas de 2 a $3 \mathrm{~m}$ de altura. Entre as situações de tempestades simuladas, as ondas provenientes de SW e SSW (figura 8) propiciaram as condições mais energéticas de mar para o litoral, seguidas das ondas de S e de SSE. Já, as ondas provenientes de SE apresentaram-se relativamente mais baixas, porém nunca inferior a $1,2 \mathrm{~m}$ de altura.

As áreas de maior concentração de energia de ondas equivalem às áreas onde foram observadas em campo maiores evidências de erosão: transposição de ondas e frente do cordão escarpada, localizadas respectivamente entre os Perfis 4 e 5 e próximo ao Perfil 2.

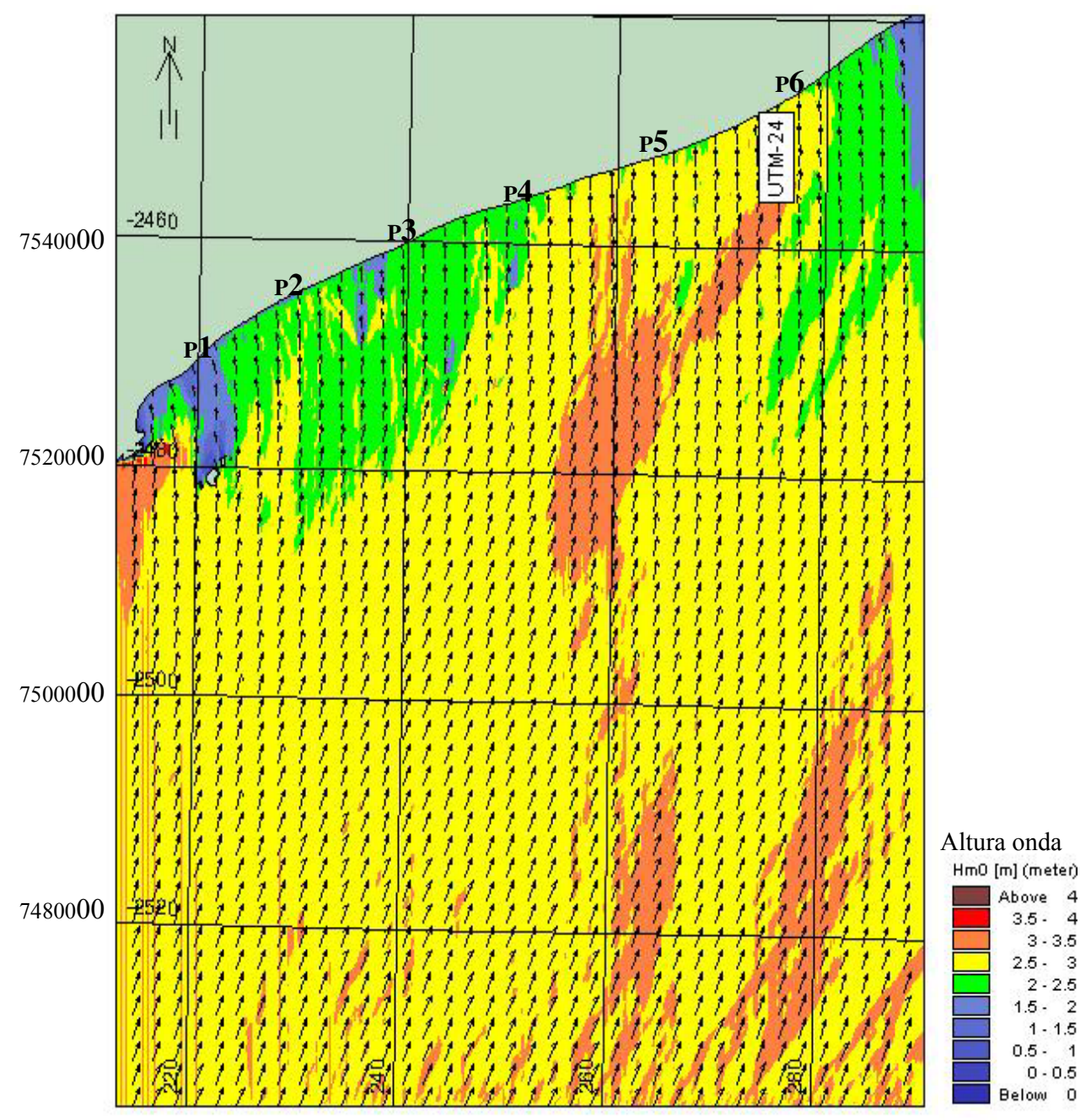

Figura 8: Refração de ondas de SSW com período de 12s Hs de 3m a partir do software MIKE 21 


\subsection{Transporte longitudinal}

Velocidades e volumes de transporte de sedimentos mais eficientes na zona de surfe foram encontrados para as situações de ondas de S, SSW e SW, alcançando valores máximos estimados de $250 \mathrm{~cm} / \mathrm{s}$ e $98 \mathrm{mil} \mathrm{m} 3 / \mathrm{dia}$, respectivamente, na localidade do Perfil 3. As menores velocidades foram obtidas nas ondas de SE e SSE $(<50$ $\mathrm{cm} / \mathrm{s}$ ) devido ao baixíssimo ângulo de incidência, mesmo apresentando ondas altas, e o volume de areia transportado estimado foi no máximo de $16 \mathrm{mil} \mathrm{m}^{3} /$ dia na localidade do Perfil 5. Nas ondulações de NE, o volume de areia estimado pode ser considerado relativamente desprezível, cerca de $380 \mathrm{~m}^{3} /$ dia.

Verificou-se uma tendência de ganho de energia do Perfil 1 para o Perfil 5, e redução no sentido do Perfil 6 para nordeste.

Constatou-se que a localidade do Perfil 6 é uma área que recebe grande volume de areia oriunda dos Perfis 1, 2, 3, 4 e 5 nas situações de tempestade. Mas o saldo geral de material transportado foi para direita, ou seja, para SW. Os perfis que apresentaram relativamente maior trânsito de areia foram o 6, seguido do 3. E o que apresentou a mais baixa mobilização de sedimento longitudinal foi o Perfil 1.

\subsection{Perfis de equilíbrio}

Os perfis topográficos medidos em campo foram comparados aos perfis de equilíbrio calculados e obtiveram os seguintes resultados (figura 9):

Perfil 1: gradiente topográfico mais suavizado, indicando maior estabilidade da linha de costa, pois apontou excesso de sedimento na antepraia, conforme o perfil de equilíbrio proposto por Dean (1977).

Perfil 2: perfil de equilíbrio típico de praia refletiva, pois apresentou uma topografia bastante íngreme. Mesmo apresentando sedimentos muito finos na antepraia, o perfil medido em campo revelou-se mais inclinado que o "ideal", mostrando-se que este não está mais na zona de sombra das Ilhas, e sim na zona de convergência das ondas difratadas, evidenciando, assim, um perfil com déficit sedimentar e, portanto, em desequilíbrio.

Perfil 3: foi o único que mostrou equilíbrio segundo a equação de Dean (1977). Nele, a antepraia superior é composta por sedimentos muito grossos e as areias finas vão gradativamente ficando lamosas em direção ao largo. Este perfil confirma a hipótese de que o substrato recente, ou seja, as areias finas e as lamas, não define a morfologia do perfil da antepraia, uma vez que a morfologia do perfil foi condicionada pela areia grossa reliquiar.

Perfis 4 e 5: apresentaram-se perfis em desequilíbrio com déficit sedimentar na antepraia, podendo estar relacionados às convergências das ondas de tempestades, as quais proporcionam ondas de maior energia principalmente no Perfil 5, e à presença de areia muito fina e de lama na antepraia.

Perfil 6: apresenta um perfil de equilíbrio com topografia mais suave, mostrando-se com excesso sedimentar. Este balanço positivo pode estar sendo provocado pela deposição de sedimentos favorecidos pela sombra provocada pelo Cabo de São Tomé às ondulações de NE, pela convergência do transporte longitudinal e pelo menor impacto das ondas de tempestades.

Os perfis de equilíbrio propostos por Dean (1977), porém calculados com o sedimento da antepraia, apresentaram um comportamento morfológico típico de uma praia dissipativa (figura 9), uma vez que o $M d$ do sedimento da antepraia média é composto por areia muito fina e silte. Desta forma, a topografia bem suavizada do perfil sugere que toda a extensão da orla do Parque esteja com forte déficit sedimentar na antepraia, e consequentemente erosão ao longo da praia. No entanto, tal situação não foi observada em campo, o que faz concluir que esta tentativa de utilizar os sedimentos da antepraia não alcançou um bom resultado de perfil teórico, condizente com as características da praia, conservando-se, assim, a sugestão de Dean (1977), de utilizar os sedimentos da face da praia.

Resultados semelhantes ocorreram com os perfis de equilíbrio calculados com o coeficiente empírico $m$ igual 0,4. Segundo Fachin (1998) apud Roso (2003), este seria o valor mais adequado para as praias do tipo refletiva. No entanto, foi constatado o oposto. A substituição do valor $m$ igual a 0,67 para 0,4 deixou os perfis teóricos com uma topografia mais suave, caracterizando, por fim, uma praia do tipo dissipativa (figura 9).

Os resultados mostraram que os perfis de equilíbrio com $m=0,4$ e com o $M d$ da antepraia não se ajustaram aos perfis medidos, apresentando declividade muito baixa. Já, os perfis calculados com o $M d$ da face da praia e com o $m=$ 0,67 se aproximaram da configuração dos perfis medidos, com ajuste perfeito no Perfil 3 e pequenos desajustes erosivos nos Perfis 2, 4 e 5 e construtivos nos Perfis 1 e 6 .

Os resultados indicaram que a forma do perfil de equilíbrio das praias ao longo do Parque de Jurubatiba está condicionada pelo substrato sedimentar reliquiar, composto por areias grossas, e não pelos sedimentos recentes encontrados na antepraia, conforme também observado por Roso (2003) nas praias do Souto e Pontal em Itaoca, sul do estado do Espírito Santo, e por Jackson et al. (2005), nas praias do norte da Irlanda. 


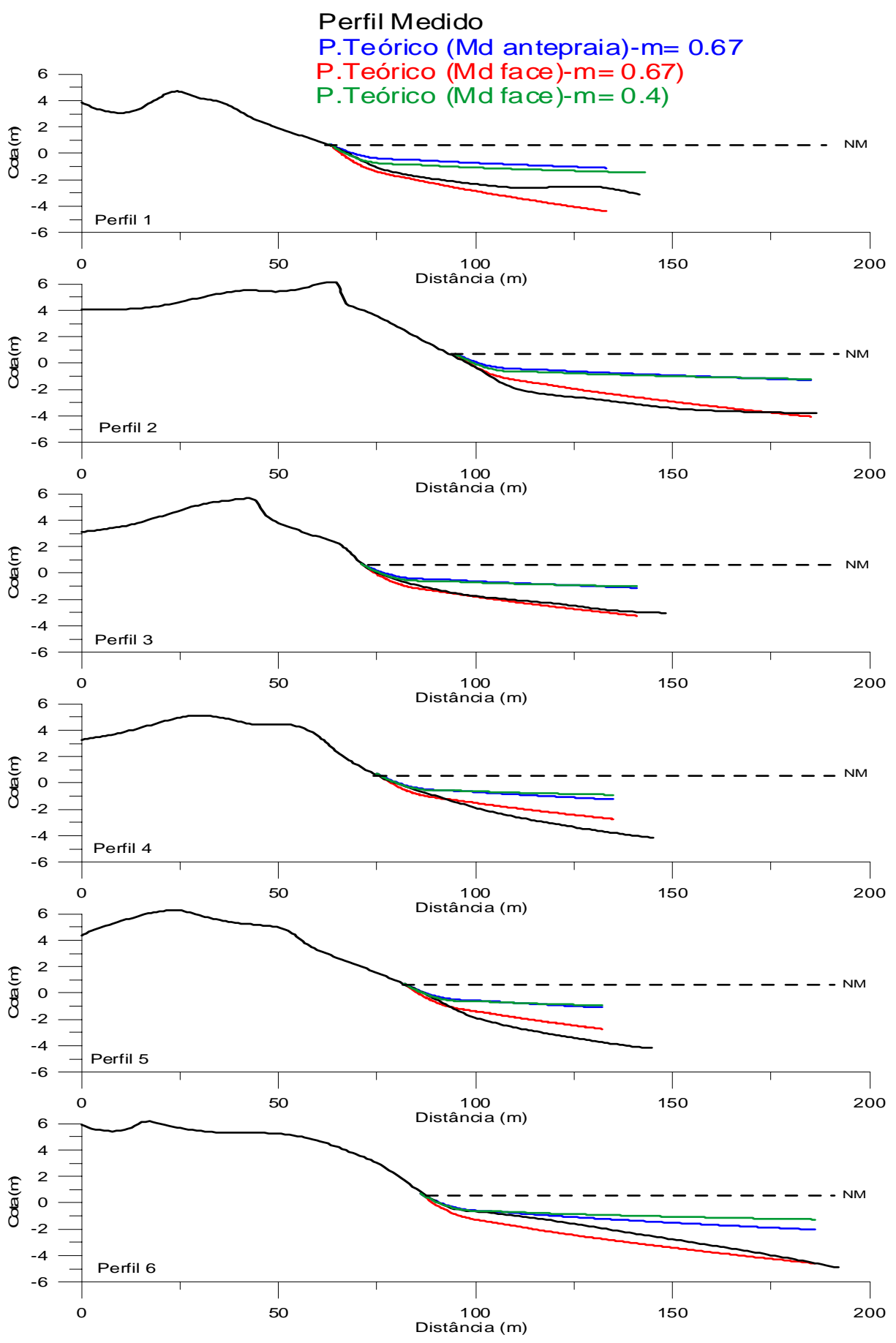

Figura 9: Perfis Teóricos de Equilíbrio calculados segundo a equação de Dean (1977)

\subsection{Transporte e deposição de sedimentos na plataforma continental interna}

Os sedimentos grossos da praia ao longo do Parque de Jurubatiba oriundos da plataforma continental interna (Martin et al. 1984), originários do rio Paraíba do Sul, quando o nível do mar situava-se mais abaixo que o atual e a desembocadura situava-se ao sul do Cabo de São Tomé (Kowsmann et al. 1979), foram retrabalhados na última transgressão marinha e subsequente regressão, formando o cordão litorâneo holocênico (Dominguez et al. 1981, Martin et al. 1984, Suguio et al. 1985).

Assim, as lamas e as areias muito finas, alóctones, dispostas paralelamente à linha de costa, acabam comprometendo o fornecimento de sedimentos para a praia, em função do trapeamento das areias grossas, impedindo o transporte transversal destes grãos, realizado por rolamento. Tal discrepância, entre os sedimentos da praia, antepraia e plataforma continental interna, evidencia que os sedimentos 
finos e lamosos são depósitos modernos, caracterizados pelas piores seleções, assimetrias positivas e curtose platicúrtica, típicos de depocentros, enquanto os depósitos reliquiares residuais são caracterizados por sedimentos grossos e médios, com bom selecionamento e assimetria negativa.

O método de McLaren (1981) utilizado para identificar o transporte de sedimentos na plataforma verificou afinamento dos sedimentos no sentido NE-SW, do Perfil 6 para o Perfil 3; no sentido E-W, do mar aberto para a costa e no sentido S-N, do arquipélago de Santana para o Perfil 2 (figura 7A). Este último, associado à assimetria negativa, direciona o trajeto do transporte para norte até a área de ocorrência da mancha de lama, que por apresentar assimetria positiva e curtose platicúrtica indica um ambiente de deposição (figura 7C).

A curtose, mesmo sendo um parâmetro de difícil interpretação (Ponçano 1986), indicou zonas de transporte identificadas pela curtose leptocúrtica entre os Perfis 5 e 6 confirmando, assim, o direcionamento do transporte em suspensão de sedimentos finos de NE para SW (figura 7D).

O grau de seleção não foi um bom indicador de transporte. Provavelmente em função da proximidade das áreas fontes dos sedimentos finos e lamosos, identificados por uma pluma de sedimentos lamosos mal selecionados, também observados por Fernandez (1995) na plataforma interna entre Macaé e Búzios.

Com base nas inferências da técnica de McLaren \& Bowles (1985), as manchas de lama indicam áreas de acumulação, confirmadas pela assimetria positiva e pela relativa convergência da curtose platicúrtica em frente aos Perfis 4 e 5 (figura 7A, C e D).

Através da técnica de Sahu (1964), foi possível reconhecer dois ambientes deposicionais, previamente definidos (praia e mar raso) por meio da comparação das características granulométricas. $\mathrm{O}$ ambiente deposicional de mar raso apresentou uma boa aproximação com as manchas de lamas (figura 10).

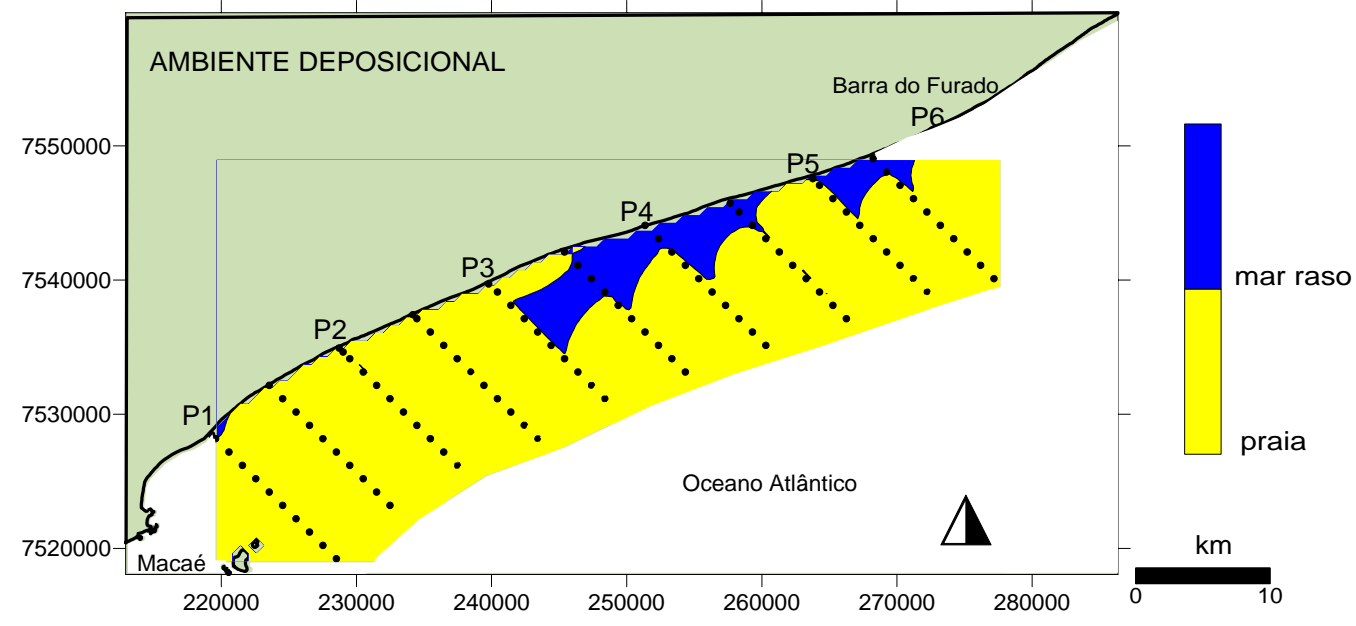

Figura 10: Mapa demonstrando dois ambientes deposicionais: mar raso agitado e praia, segundo a técnica de Sahu (1964)

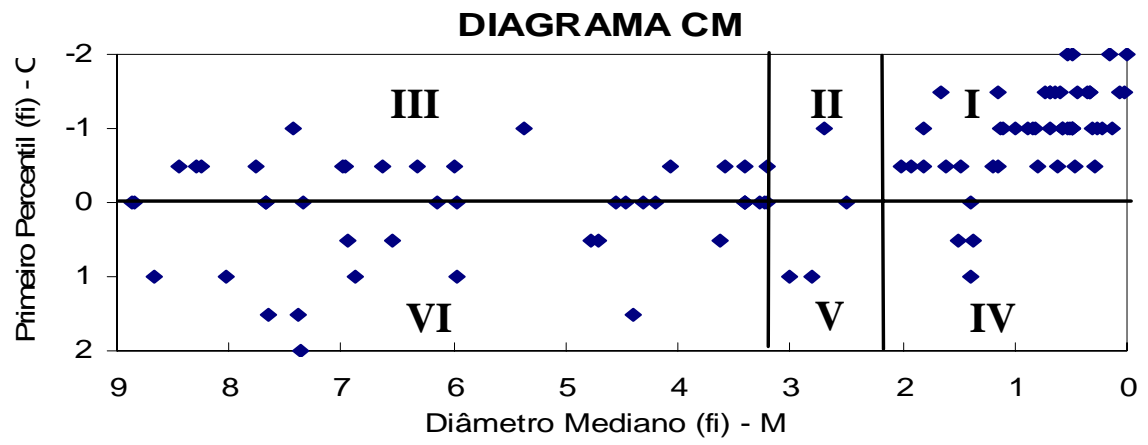

Figura 11: Diagrama CM dos sedimentos coletados na plataforma continental interna 
Os diferentes processos de sedimentação foram identificados no Diagrama CM proposto por Passega (1964, figura 11).

Segundo o Diagrama CM os sedimentos dos setores I e II são constituídos de areia grossa e média, respectivamente, e transportados por rolamento. O setor III é constituído por sedimentos finos e lamosos transportados em suspensão, e os grãos grossos por rolamento. Os setores IV, V e VI representam sedimentos transportados principalmente em suspensão, pois apresentaram grãos com $M d$ mais finos, e, quando os sedimentos são grossos e médios (entre 0 e -2 fi), estes são transportados por rolamento, estando submetidos à elevada turbulência.
A figura 12 mostra que grande parte da plataforma continental interna apresentou transporte por rolamento (presença de areia grossa). O transporte predominantemente em suspensão corresponde às áreas de deposição sob condições de elevada, moderada ou baixa turbulência (presença de areias fina e muito fina e lama). Esta distribuição sugere que estes sedimentos formam um estrato recentemente depositado sobre o material grosso reliquiar e que provêm, provavelmente, da paleodesembocadura ou da desembocadura atual do rio Paraíba do Sul, ou até mesmo do rio Macaé, impulsionados por suspensão pelas correntes litorâneas.

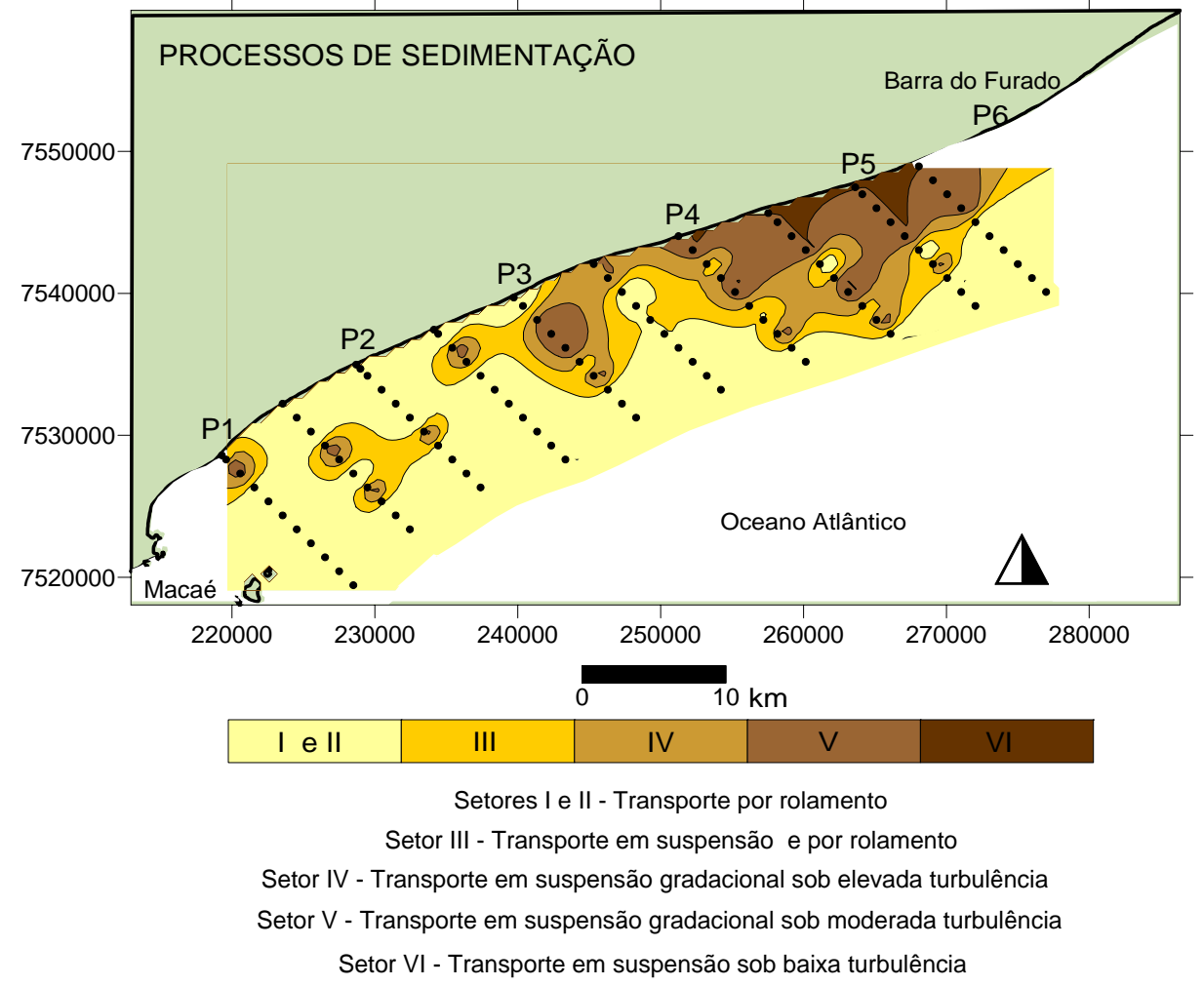

Figura 12: Diferentes processos de sedimentação identificados no diagrama CM sugerido por Passega (1964)

\subsection{Principais agentes responsáveis pelo processo erosivo do sistema praia-antepraia}

A presença de lama na antepraia e na plataforma continental interna encobrindo os sedimentos grossos que provavelmente seriam transportados em direção à praia; 0 grau de exposição do litoral às condições de ondas de tempestades; a convergência das ondas em trechos específicos; o direcionamento do transporte de lama para trechos bem próximos ao litoral; e a proximidade dos rios Paraíba do Sul e Macaé, que fornecem sedimentos finos e lamosos, são, possivelmente, os principais agentes responsáveis pela dinâmica sedimentar do sistema e, consequentemente, pelos processos erosivos ocorridos na área, sinalizando uma tendência de retrogradação da linha de costa, morfologicamente dinâmica e frágil.

A figura 13 segmenta o litoral de acordo com a intensidade e as características erosivas encontradas em campo e nos dados analisados.

Os segmentos foram definidos conforme as características do cordão, da praia e da plataforma continental interna. Foram analisados os seguintes critérios: condições do cordão litorâneo (extensão e presença de vegetação); presença de lagunas; indicadores de erosão (marcas de transposição de ondas, cordão escarpado e densidade de vegetação); e o $M d$ do sedimento da antepraia e da plataforma. 


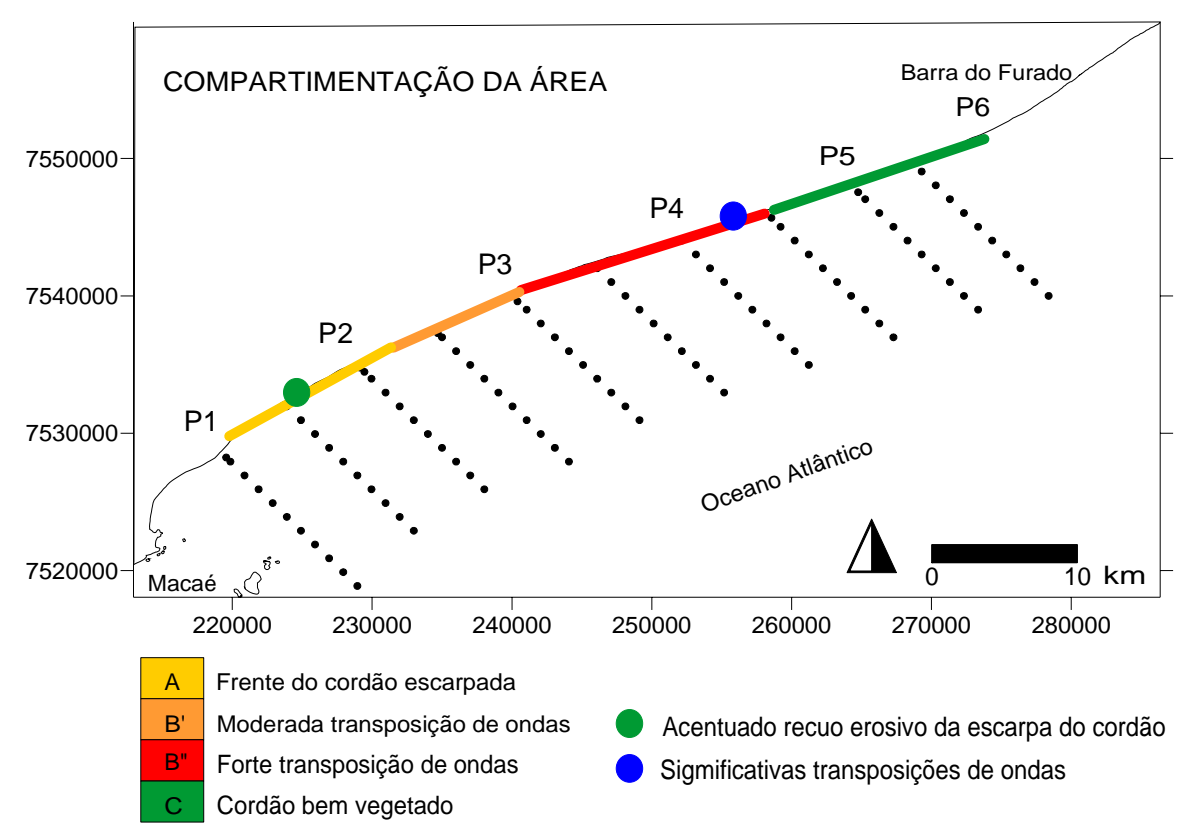

Figura 13: Mapa de compartimentação da área conforme as características erosivas observadas

O segmento "A" é caracterizado pela presença de estrada e tubulação de gás da Petrobrás, situadas sobre o cordão; com vegetação bem preservada, exceto próximo ao Perfil 1, onde a área é bastante urbanizada e não pertence mais aos limites do Parque; e as lagunas aparecem logo após o Perfil 2. O segmento é marcado pela forte erosão do cordão, já bastante escarpado, provocando um significativo estreitamento da estrada num trecho aproximado de $1,5 \mathrm{~km}$ de extensão, comprometendo, inclusive a tubulação de gás (figura 14: foto 1). Este trecho crítico de erosão coincide com uma pequena mas significativa mancha de areia fina e lama distribuída na antepraia e na plataforma continental interna adjacente.

O segmento "B" é caracterizado pelas marcantes zonas de transposição de ondas (figura 14: Foto 2). Estas são mais intensas no subsegmento "B". Neste local as ondas, em momento de tempestade e maré alta, ultrapassam o cordão litorâneo, deixando-o mais baixo, mais estreito e sem vegetação, confundindo-se muitas vezes com a praia. No subsegmento "B"' as zonas de transposição são mais brandas. Ao longo de todo o segmento estão presentes inúmeras lagunas à retaguarda do cordão, estando muitas vezes bem próximas da praia, indicando, desta forma, um alto potencial de fragilidade do cordão. Na antepraia e na plataforma continental interna adjacente, é notável a presença de areia muito fina a lama.

O segmento "C" é caracterizado por um cordão litorâneo mais desenvolvido ( $\pm 70 \mathrm{~m}$ de largura), bastante vegetado com ampla planície no reverso (figura 11: foto 3). A vegetação torna-se mais rala, juntamente com as evidências de erosão e transposição de ondas, à medida que se aproxima do segmento "B" e das lagunas. Neste segmento, não foram observados significativos indicadores de erosão na praia e no cordão, mesmo apresentando areia muito fina na antepraia. Desta maneira, a presença de sedimentos finos e lamosos na parte submersa adjacente, principalmente ao Perfil 5, pode evidenciar uma tendência erosiva para este trecho, que já apresenta déficit sedimentar na antepraia e convergência das ondas de maior energia.

\section{Conclusão}

Considerando uma análise de curto e médio prazo (meses a décadas), as fortes evidências erosivas observadas na orla do Parque não sugerem ainda um processo erosivo evolutivo, uma vez que a eficiente corrente longitudinal mantém o abastecimento sedimentar do sistema sustentado pela predominância das ondulações do quadrante NE. Já, numa escala de longo prazo, este litoral poderá estar seriamente comprometido caso haja um bloqueio natural ou forçado dos sedimentos trabalhados pela corrente longitudinal, intensificação das tempestades, obstrução das fontes supridoras de sedimentos ou aumento do nível do mar. Este prognóstico é agravado pelo próprio histórico geológico-geomorfológico da linha de costa, que naturalmente se caracteriza como retrogradante, e, por isto, independentemente de qualquer prognóstico evolutivo da linha de costa, deve ter sua urbanização fortemente desestimulada.

Várias evidências de erosão encontradas em campo como transposição de ondas, cordão escarpado, desajuste nos perfis de equilíbrio, ausência de vegetação sobre o cordão e estreitamento do mesmo -, quando associadas às distribuições dos sedimentos da zona submarina, às características morfológicas da praia e da antepraia e ao grau de exposição às ondas de tempestades, permitem inferir os principais agentes do processo erosivo do sistema.

Os perfis de equilíbrio elaborados com a equação de Dean (1977) aproximaram-se bastante da configuração dos perfis medidos, com ajuste perfeito no Perfil 3 e pequenos 
desajustes negativos nos Perfis 2, 4 e 5 e positivos nos Perfis 1 e 6.
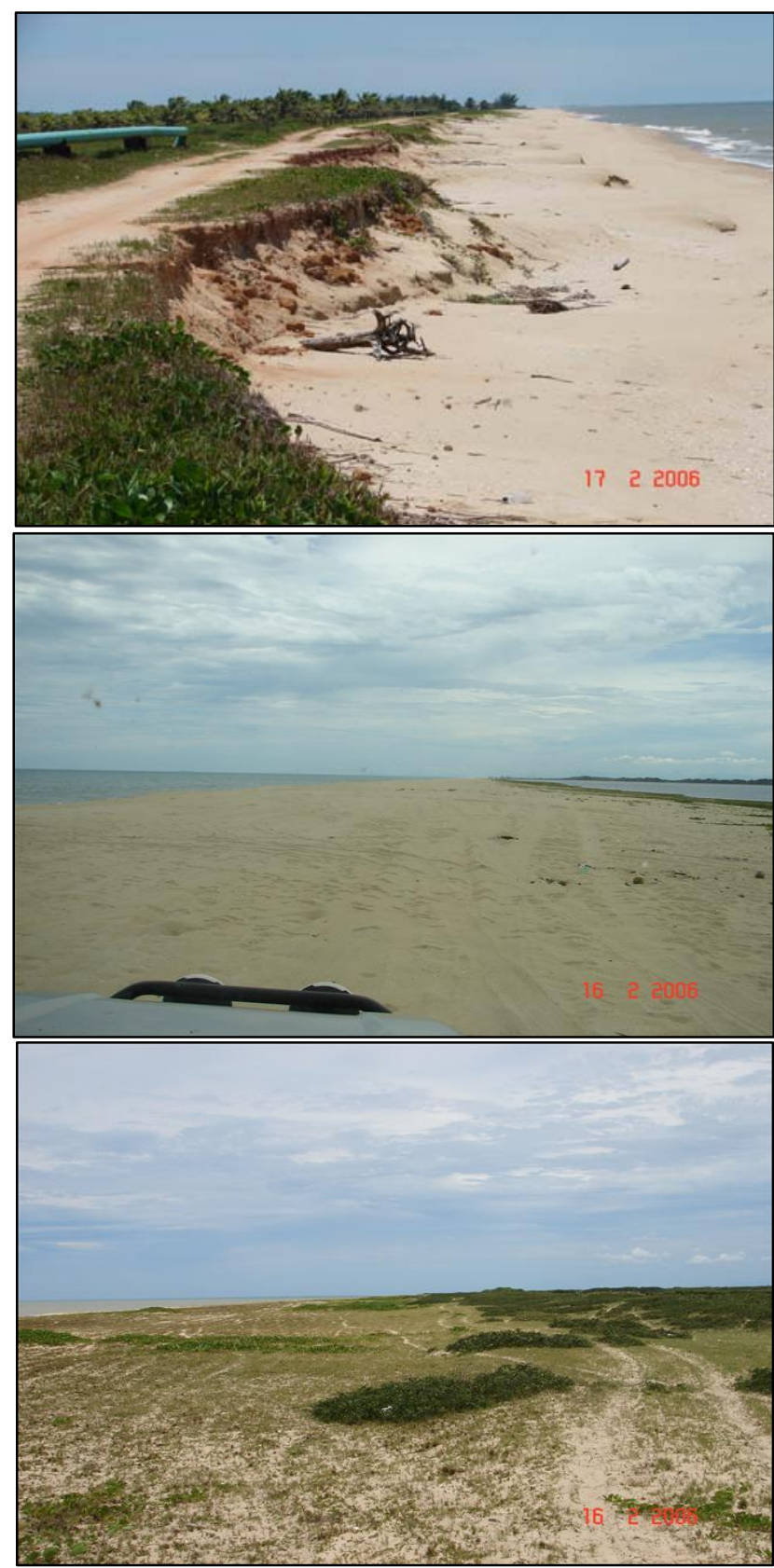

Figura 14: Foto 1: cordão escarpado comprometendo a estrada e a tubulação de gás (Coord. 230990; 7535888); Foto 2: trecho com transposição de ondas sobre o cordão que quase alcança a laguna (Coord. 255734; 7545326); Foto 3: cordão litorâneo extenso e bem vegetado (Coord. 274088; 7551700), (Fotos: Dieter Muehe)

Estes resultados indicaram que as declividades dos perfís transversais não estão sendo definidas pelo sedimento moderno, e sim pelo material reliquiar composto por areia grossa. O ajuste encontrado no Perfil 3, composto por areia grossa na antepraia e por declividade típica de praia refletiva, levou a concluir que os perfis restantes mostram-se desajustados na presença de areia muito fina e lama na antepraia, ao apresentarem perfis teóricos de equilíbrio típicos de praias dissipativas.

O emprego do $M d$ dos sedimentos coletados na antepraia mostrou-se insatisfatório para esta praia, pois se apresentaram muito suavizados, incompatíveis com o perfil medido. Da mesma forma, apresentaram-se os perfis de equilíbrio elaborados com o coeficiente $m=0,4$, indicado para praias refletivas, mas que modelou o perfil com uma topografia típica de praia dissipativa. Deste modo, a adoção do coeficiente $m=2 / 3$ proposto por Dean (1977) mostrouse mais adequada para a interpretação dos perfis da orla analisada.

A convergência do transporte de lama na plataforma continental interna sugere que este material tende a aumentar, encobrindo cada vez mais os sedimentos reliquiares.

Neste caso, a transferência de sedimentos arenosos da plataforma em direção à costa pode estar comprometida, uma vez que a presença de lama junto à costa pode impedir que as areias grossas abasteçam a praia e o cordão.

Mesmo sendo difícil distinguir se as características erosivas encontradas são o resultado de eventos esporádicos ou a indicação de uma tendência, os diversos indicadores analisados convergem para um diagnóstico de instabilidade potencial mais generalizada, quando, associado à histórica tendência evolutiva retrogradante e à intensificação esperada dos processos costeiros ligados às variações climáticas globais, permitem prever a consolidação da tendência retrogradante deste segmento costeiro.

\section{Referências bibliográficas}

Alves E.C., Ponzi V.R.A. 1984. Características morfológico-sediemntares da Plataforma Continental e Talude Superior da Margem Continental. In: Congresso Brasileiro de Geologia, 33, 1984, Rio de Janeiro. Anais... p.1629-1642.

Bastos A.C. 1997. Análise morfodinâmica e caracterização dos processos erosivos ao longo do litoral norte fluminense, entre Cabiúnas e Atafona. Dissertação de Mestrado. Pós-Graduação em Geologia e Geofísica Marinha, Universidade Federal Fluminense, 133 p.

Bittencourt A.C.S.P., Boas G.S.V. E Farias F.F. 1992. Variações direcionais nos parâmetros granulométricos: um indicador apropriado para o sentido da deriva litorânea. Revista Brasileira de Geociências. São Paulo, v. 22, n. 1, p. 100-106, março de 1992

Bruun P. 1954. Coastal erosion and the development of beach profiles. Waterways Experiment Station, U.S. Army Corps of Engeeniers, Technical Memorandum. [s.1.], v.44.

Carvalho V.C., Rizzo H.G. 1994. A zona costeira brasileira: subsídios para uma avaliação ambiental. Ministério do Meio Ambiente e da Amazônia Legal. Brasília, MMA, $211 \mathrm{p}$.

Cowell J.P., Hanslow D.J., Meleo J.F. 1999. The shoreface. In: Short A.D. (ed.). Handbook of beach and shoreface morphodynamics. John Wiley \& Sons, Ltd., 39-71.

Dean R.G. 1991. Equilibrium beach profiles: characteristics and applications. Journal of Coastal Research, 7:53-84.

Dean R.G. 1977. Equilibrium beach profiles: US Atlantic and Gulf Coasts. Ocean Engineering Techinical Report, 12:1-45.

Dias G.T.M., Silva C.G. 1984. Geologia de depósitos arenosos costeiros emersos - exemplos ao longo do litoral fluminense. In: Lacerda L.D., Araújo D.S.D., Cerqueira R., Turcq B. (Eds.). Restingas: origem, estrutura e processos. Universidade Federal Fluminense. Anais do Simpósio sobre Restingas Brasileiras, 47-60 p.

Dominguez J.M.L., Bittencourt A.C.S.P. 1994. Utilização de Padrões de Sedimentação Costeira como Indicadores Paleoclimáticos Naturais (Proxies). Revista Brasileira de Geociências. São Paulo, v. 24, n. 1, p.3-12, março de 1994. 
Dominguez J.M.L., Bittencourt A.C.S., Martin L. 1981. Esquema evolutivo da sedimentação quaternária nas feições deltaicas dos rios São Francisco (SE/AL), Jequitinhonha (BA), Doce (ES) e Paraíba do Sul (RJ). Revista Brasileira de Geociências, 11: 227237.

Fernandez G.B. 1995. Cobertura sedimentar recente e batimetria da plataforma continental interna entre Macaé e o Cabo de Búzios, RJ: Resultados da operação PITA II. Monografia de Graduação. Graduação em Geografia, Universidade Federal do Rio de Janeiro, $40 \mathrm{p}$.

Folk R.L., Ward W.C. 1957. Brazos river bar: a study in the significance of grain size parameters. Journal of Sedimentary Petrology, 27: 3-26.

Horikawa K. 1972. Coastal engineering: an introducion to ocean engineering. Halsted Press Book, Toronto e New York, 402p.

Jackson D.W.T., Cooper J.A.G., Del Rio L. 2005. Geologycal control of beach morphodynamic state. Marine Geology, 216: 297-314.

Komar P.D. 1976. Selectve longshore transport rates or different grainsize fraction within a beach. Journal of Sedimentary Petrology, 47:1444-1453.

Kowsmann R.O., Vicalvi M.A., Costa M.P.A. 1979. Considerações sobre a sedimentação quaternária na plataforma continental brasileira entre Cabo Frio e o rio Itabapoana. Notícia Geomorfológica, 19:41-58, n. 37/38.

Martin L., Suguio K., Flexor J.M., Dominguez J.M.L., Azevedo A.E.G. 1984. Evolução da planície costeira do rio Paraíba do Sul (RJ) durante o quaternário: influência das flutuações do nível do mar. In: Anais... Congresso Brasileiro de Geologia, 33:84-97.

McLaren P., Bowles D. 1985. The effects of sediment transport on grain-size distributions. Journal of Sedimentary Petrology, 55:457470, n. 4.

McLaren P. 1981. An interpretation of trends in grain size measures. Journal of Sedimentary Petrology, 51:611-624, n. 2.

Mendes J.C. 1984. Elementos de Estatigrafia. São Paulo: Queiroz.

Muehe D. 2006. Método de Levantamento Topo-Batimétrico do Perfil do Sistema Praia-Antepraia. Revista Brasileira de Geomorfologia. 5: $95-100$.

Muehe D. 2005. Aspectos gerais da erosão costeira no Brasil. Revista de Geografia da UFC, 7:97-110.

Muehe D. 2004. Definição de limites e tipologias da orla sob aspectos morfodinâmico e evolutivo. In: Ministérios do Meio Ambiente e do Planejamento, Orçamento e Gestão. Projeto Orla: subsídios para um projeto de gestão, Brasília: MMA e MPO, p.13-32.

Muehe D. 2001. Geomorfologia Costeira. In: Cunha S.B., Guerra A.J.T (Org). Geomorfologia: uma atualização de bases e conceitos. 4 ed. Rio de Janeiro: Bertrand Brasil, Cap. 6.

Muehe D., Valentini E. 1998. O litoral do estado do Rio de Janeiro: uma caracterização ambiental. FEMAR, Rio de Janeiro, 99p.
Muehe D. 1998a O litoral brasileiro e sua compartimentação. In: Guerra A.J.T., Cunha S.B. (Eds.) Geomorfologia do Brasil. Bertrnand Brasil, Rio de Janeiro, p.273-350.

Muehe D. 1998b. Estado morfodinâmico praial no instante da observação: uma alternativa de identificação. Revistas Brasileiras de Oceanografia, 46:157-169, n. 2.

Muehe D. 1989. Distribuição e caracterização dos sedimentos arenosos da plataforma continental interna entre Niterói e Ponta Negra, RJ. Revista Brasileira de Geociências, 19:25-36.

Passega R. 1964. Grain size representation by CM partterns as a geological tool. Journal of Sedimentary Petrology, 34:830-847, n. 4

Ponçano W.L. 1986. Sobre a interpretação ambiental de parâmetros estatísticos granulométricos: exemplos de sedimentos quaternários da costa brasileira. Revista Brasileira de Geociências, 16:157-170, n. 2.

Roso R.H. 2003. Avaliação da aplicabilidade de conceitos da morfodinâmica de praia no planejamento de desembarques anfíbios. Dissertação de Mestrado. Pós-Graduação em Geografia, Universidade Federal do Rio de Janeiro, $179 \mathrm{p}$.

Sahu B.K. 1964. Depositional mechanisms from the size analysis of clastic sediments. Journal of Sedimentary Petrology, 34: 73-83.

Selley R.C. 1982. An introduction to sedimentology. 2 ed. Academic Press, Florida, $417 \mathrm{p}$.

Silva C.G., Patchineelam S.M., Neto J.A.B., Ponzi V.R.A. 2004 Ambientes de sedimentação costeira e processos morfodinâmicos atuantes na linha de costa. In: Neto J.A.B., Ponzi V.G.A., Sichel S.E. (Eds.). Introdução à Geologia Marinha. Interciência, Rio de Janeiro, $175-218 \mathrm{p}$.

Silva C.G. 1987. Estudo da evolução geológica e geomorfológica da região da Lagoa Feia, RJ. Dissertação de Mestrado. Pós-Graduação em Geologia, Universidade Federal do Rio de Janeiro, 116 p.

Souza M.H.S. 1988. Clima de ondas do norte do estado do Rio de Janeiro. Dissertação de Mestrado. Pós-Graduação em Engenharia Oceânica, Universidade Federal do Rio de Janeiro/ COPPE, 181p.

Suguio, K. 1992. Dicionário de Geologia Marinha: com termos correspondentes em inglês, francês e espanhol. 15 ed. São Paulo: T.A. Queiroz. $171 \mathrm{p}$.

Suguio K., Martin L., Bittencourt A.C.S.P., Dominguez J.M.L., Flexor J.M., Azevedo A.E.G. 1985. Flutuações do nível relativo do mar durante o quaternário superior ao longo do litoral brasileiro e suas implicações na sedimentação costeira. Revista Brasileira de Geociências, 15:275-286, n. 4.

Wentworth C.K. 1922. A escale of grade and class terms for clastic sediments. Journal of Geology. [s.l.], paginação irregular.

Recebido 16 de outubro de 2009 Aceito 19 de fevereiro de 2010 